\title{
Aproximación al discurso alimenticio en E nsalada de pollos de José Tomás de Cuéllar
}

\author{
Josefina María Moreno de la Mora*
}

Resumen:

L a linterna mágica es una serie de novelas, relatos de costumbres, artículos y poemas que bajo este título publicó José Tomás de Cuéllar (1830-1894), en más de 24 tomos y dos épocas, entre 1871 y 1892.

Inicia la serie E nsalada depollos (1869), una peculiar novela (no de las mejores de su autor) en que la acción se entreteje con las numerosas digresiones moralizantes de la instancia narrativa, $y$ en ambas predomina el discurso alimenticio, que se presenta de varias formas.

Se establece una sistemática de las funciones que adquiere el discurso alimenticio, entre las cuales destacan: la comida como parte de una descripción costumbrista; figuras retóricas sobre la comida como recurso de la instancia narrativa; figuras retóricas sobre la comida en boca de los personajes; la comida como marcador de una clase social; la mesa como antecedente (o sustituto) de la cama, y la comida y la bebida como recurso persuasivo.

Así, E nsalada de pollos se circunscribe (aunque en muy distintas circunstancias) en una tradición en la que los alimentos han constituido un tema literario de gran importancia desde las épocas más remotas. Baste recordar ejemplos tan notables como La 0 disea, E 1 Satirión, E 1 ingenioso hidalgo D on Q uijote de L a Mancha, L a vida del Buscón llamado D on Pablos, E 1 L azarillo de Tormes, y, por supuesto, L as aventuras de $\mathrm{G}$ argantúa y Pantagruel.

${ }^{*}$ Universidad de Guadalajara. 
En el último tercio del siglo diecinueve mexicano surge un proyecto literario: La linterna mágica; serie de relatos de costumbres, artículos y poemas que bajo este título publicó su autor, José Tomás de Cuéllar (1830-1894), en más de 24 tomos y dos épocas, entre 1871 y 1892.

Cuéllar - diplomático, pintor y fotógrafo aficionado, dramaturgo olvidado, periodista, cadete del Colegio Militar durante la invasión norteamericana de 1847 e impulsor del reconocimiento a los llamados "niños héroes"- se confiesa inspirado en L a comedia humana de Balzac. Adopta el pseudónimo de "Facundo" para proyectar las imágenes que promete tan sugerente título y utiliza como telón de fondo la capital mexicana en un momento de transición: desde la llamada guerra de Reforma, o guerra de Tres Años, el período que le sucede, el gobierno de Juárez; la intervención francesa, el segundo imperio, hasta la república restaurada.

Inaugura la serie con E nsalada de pollos, publicada como folletín en la revista La Ilustración Potosina en 1869, y reeditada en 1871 y 1890. (La versión de 1871 es el objeto de este trabajo.)

La trama se basa en uno de los tópicos favoritos de la época: la caída de Concha, una joven pobre e ignorante, en el mundo de la prostitución. Sin embargo, lo que confiere un carácter peculiar al relato es el uso particularísimo que se hace del lenguaje.

Mucho se ha escrito sobre la presencia en la obra de Cuéllar de rasgos que denotan su calidad de artista plástico. Sin embargo, en la descripción de los personajes esto no se manifiesta. La mayor parte de ellos (sobre todo los femeninos) son apenas esbozados de una manera casi fragmentaria. La instancia narrativa sólo se detiene en la descripción física de determinados personajes: aquellos que presentan características que pudieran considerarse en mayor o menor medida como defectos físicos.

Un claro ejemplo de la parquedad en las descripciones es el que se proporciona de Sara y Ernestina, niñas ricas amigas de Concha: "Sara estaba clorótica. Ernestina también" (De Cuéllar 177).

En general es notable la mínima cantidad de imágenes generadas a partir de la vista (lo cual es paradójico, si se toma en cuenta que, como hemos dicho, críticos e historiadores de la literatura como 
Castro Leal 1994, Glantz [coord.] 1997, y Pérez Martínez 1985, entre otros, tratan de establecer una relación entre la obra pictórica de Cuéllar y su obra literaria). En cambio las imágenes elaboradas a partir de las percepciones del sentido del gusto son las más abundantes, aunque también hay algunas que se refieren al olfato, al tacto y al oído.

D e acuerdo con los conceptos de los neoretóricos, en especial de Le Guern (1990) y el Grupo M (1984), la metonimia impera desde el título, ${ }^{1}$ donde se aprovecha el hecho de que en el habla popular de la época cierta clase de jóvenes eran denominados con el término connotativo de "pollos", para establecer una relación con el sema "ensalada", que es definido como "Hortaliza o varias hortalizas mezcladas, cortadas en trozos y aderezadas con sal, aceite, vinagre y otras cosas" (y, en una segunda acepción, "Mezcla confusa de cosas sin conexión"), que pertenece a un mismo semema: el discurso alimenticio. A partir de estos elementos se construirá todo un sistema metonímico que incluye desde el tipo de tropos que utiliza la instancia narrativa y se ponen en voz de los personajes, hasta los nombres de algunos de ellos. Incluso este sistema trasciende a tal grado que el discurso alimenticio cobra una importancia inusitada aun cuando se está utilizando en sentido literal.

${ }^{1} \mathrm{Si}$ bien pudiera aducirse que denominar "pollos" a los jóvenes no es una metonimia (ya que son semas que no pertenecen a un mismo semema), sino una metáfora, el contexto que proporciona el uso del término en el habla popular, más la relación que se establece entre la definición de joven (humano de corta edad) y la de pollo (ave de corta edad, en especial la cría de la gallina), deriva en un proceso metonímico que dará lugar a todo un sistema de metonimias. Recordemos con Hjelmslev (164) que "D ada la no restrictividad (productividad) de un texto, siempre habrá 'traducibilidad', que aquí significa sustitución de la expresión, entre dos signos cada uno de los cuales pertenezca a una clase de signos propia, y siendo solidaria a su vez esta clase de signos con su respectivo connotador". Y con Van Dijk (117) que "una teoría empíricamente adecuada de la literatura tiene al menos dos componentes principales: una teoría de textos literarios y una teoría de la comuni-cación yel contexto literarios, teorías que están, claro, sistemáticamente relacionadas". 
Los alimentos han constituido un tema literario de gran importancia desde las épocas más remotas. Baste recordar ejemplos tan notables como L a 0 disea, E I Satiricón, El ingenioso hidalgo D on Q uijote de La Mancha, La vida del Buscón llamado D on Pablos, El Lazarillo de Tormes, y, por supuesto, L as aventuras de $\mathrm{G}$ argantúa y Pantagruel.

Utilizar el discurso alimenticio como fuente de figuras literarias nos remite de manera directa a la tradición judeocristiana, en especial al libro del $\mathrm{C}$ antar de los cantares. Esta tradición se reafirma durante la Edad Media por influencia eclesiástica (Curtius 119).

En E nsalada de pollos, Cuéllar cita a Anthelme Brillat-Savarin, autor de Fisiología del gusto, o M editaciones de gastronomía trascendente, publicada en Francia en $1825 .^{2}$ Esta obra tiene apartados tales como "Teorías sobre el freír", "Historia filosófica de la cocina", "Variedad". En la sección de "Aforismos del profesor para servir de prolegómenos a su obra y de base eterna a la ciencia", afirma: "El destino de las naciones depende de la manera como se alimentan"; "Dime lo que comes y te diré quién eres"; "Se aprende a ser cocinero, pero a preparar asados no se aprende, se nace"; "Invitar a alguien a comer significa encargarnos de su felicidad durante todo el tiempo que permanezca bajo nuestro techo" (citado por C. Cordié 198).

E nsalada de pollos muestra como una de sus características más evidentes la gran cantidad de referencias explícitas a los alimentos que se encuentran en ella, las cuales cobran tal relevancia que sin este elemento sería imposible concebir el texto.

En algunas ocasiones se trata de los alimentos procesados para su consumo; en otras, de las materias primas para elaborarlos (como granos, semillas y vegetales, incluso algunos que son propios más bien del consumo animal). Es también recurrente el uso de verbos que refieren a las acciones propias de comer o beber, que se usan tanto en sentido literal como figurado. Si tomamos en cuenta las funciones que se asignan a la comida en estos fragmentos, es posible establecer en primera instancia esta clasificación:

${ }^{2}$ Título que inspiró a Balzac para trasladarlo a su Fisiología del matrimonio, y con el que comparte el afán positivista de dar validez a los conceptos al relacionarlos con el discurso científico. 
1. Metonimias en voz de la instancia narrativa.

2. Metonimias en voz de los personajes.

3. La comida como parte de una descripción costumbrista (elemento ambientador).

4. La comida como marcador de una clase social.

5. La mesa como antecedente (o sustituto) de la cama.

6. La comida y la bebida como recurso persuasivo.

7. O tras funciones de la bebida.

\section{1) Metonimias en voz de la instancia narrativa}

Posiblemente son las más abundantes. Se emplean en un afán de ironía descriptiva “...dos niñas dulces doraban naranjas agrias, mientras dos viejas agrias se acababan los dulces..." (40), o hasta con grave intención filosófica, en las largas digresiones moralizantes de la voz narrativa "Labradores de este campo que se llama vida, recogemos indispensablemente los frutos de nuestra siembra de ayer", (136). Pasan además por una amplia gama de matices: "...el traje de Concha fue el platillo de todas las conversaciones" (25); "En seguida Arturo prorrumpió en asquerosos denuestos, en insultos soeces, en palabras inmundas y quería comerse a Pío Blanco" (141-42); "Ya hemos dicho que en el pollo la tercería es una de sus comiditas..." (96); "Pío Blanco estaba en verdadero punto de pollo frito" (172), etcétera.

Cabe aclarar que la instancia narrativa constantemente se autodefine como el autor de la ensalada, y hace múltiples alusiones a ella. Entre muchas otras: “...en esta ensalada nos hemos propuesto que el lector coma las lechugas sin saber en dónde se cortaron" (97), y, para introducir la conclusión del texto, "Perdonadnos, entre tanto, si esta ensalada no sigue revolviéndose, y la damos tan pronto por suficientemente bien condimentada" (226). 


\section{2) Metonimias en voz de los personajes}

En este rubro se incluyen expresiones que se suponen usuales en el habla coloquial de la época. Así, cuando una vecina intriga contra Concha con su madre, doña Lola, ésta afirma: "-D éjela usted... que se vayan las visitas y nos comeremos el gallo. Yo le haré ver..." (53). Cuando doña Lola reprende a su hija y se desata el conflicto (Arturo rapta a Concha), la madre recapacita: "-Quiere decir que me la tenían amasada - dijo doña Lola, poniéndose en jarras-pero ya lo verán, qué buena cárcel se maman..." (69). Sin embargo, reflexiona el compadre José de la Luz: "-Pero la cárcel no come, como dice el dicho..." (70).

\section{3) La comida como parte de una descripción costumbrista (elemento ambientador)}

El ejemplo idóneo se da en el capítulo III de la segunda parte, en donde para situarnos en el tiempo y describir el paisaje se emplean como referencia indispensable los vendedores de comida:

La noche es hermosísima, y en el reloj de la Catedral acaban de sonar las doce y media: del portal de las Flores se retira el último figón improvisado sobre una mesa, y todavía en los dos extremos del portal de Mercaderes permanecen, soñolientos y silenciosos, dos dulceros, iluminados por la fuerte luz de un quinqué de petróleo. (190)

\section{4) La comida como marcador de una clase social}

Es uno de los aspectos más determinantes del uso del discurso alimenticio en el relato, ya que subraya aspectos sociales, económicos y aspiracionales muy específicos: 
Pío Prieto siguió este torrente, y la primera vez que pidió un helado en Fulcheri pensó con tristeza en la hojalatería; se le figuraba que el mármol de las mesas, el tapiz aterciopelado de los asientos, los espejos y las lámparas de gas le reprendían por ser hojalatero; pensaba que si en un corro de sus nuevos amigos, pollos finos en su mayor parte, llegaba a saberse que Pío Prieto soldaba tinas y calentaderas, sufriría la más pesada de las bromas y no sabría qué hacer. (95)

Así como Pío Prieto de pronto toma conciencia de la clase social a la que quiere tener acceso, gracias a un helado, Concha demuestra que no es tan sofisticada como quiere parecer debido a una sopa:

Pío Blanco pidió una sopa de ostiones para los tres.

- ¿Sopa? - dijo Concha haciendo un gesto graciosísimo.

-Sopa, Concha, sopa de ostiones.

- ¿A estas horas?

- ¡O h!, ese es el chic, los ostiones son nuestra comida favorita, ¿no es verdad, Arturo? Ya sabes.

Puso el criado la sopera y Pío Blanco hizo platos.

Concha observó para sí que aquello no tenía cara de sopa; por lo menos no se parecía a la de tortilla, ni a la de fideos; tomó algunas gotas en la punta de la cuchara y la probó: la encontró detestable.

- D e tomar sopa - pensó Concha- preferiría yo de tallarín, como la que hace mi mamá. (124)

Lo cual hace que Pío Blanco aconseje a Arturo: “...si quieres ser feliz, es preciso que alimentes a esta hechicera beldad con los productos culinarios más en analogía con las costumbres modernas" (126). Esta cita refuerza la idea del determinismo positivista, en el sentido de que la alimentación influye en la esencia humana.

En contraste, cuando la vecindad en pleno se entera de que don Jacobo Baca, el padre de Concha, ha sido ascendido a coronel, Casimira propone: 
-...O igan, vecinas, vamos a felicitar a doña Lola y a obligarla a que nos dé tamales y atole de leche, como albricias de la buena noticia.

-No, mejor chongos - dijo una vecina.

- Mejor mole de guajolote -agregó otra.

- ¡Eso es! Cada uno va pidiendo, no se puede decir nada, jhambrientos!

-Hambrienta tú, que quieres tamales luego. (194)

Así, la comida tradicional mexicana aparece reservada a las clases bajas, mientras que la extranjera es un indudable símbolo de la posición social de los ricos (además, los pobres deben ingeniárselas para conseguir comida gratis). Hasta en la cárcel se observa esta distinción: “Como se trataba de un pollo fino se ablandó el alcaide, y el separo de Pío era invadido frecuentemente por una bandada de pollos que formaban corro, improvisaban almuerzos y llevaban dulces, pasteles, puros y botellas de coñac al preso" (150).

\section{5) La mesa como antecedente (o sustituto) de la cama}

Es lógico que por la época en que el texto fue escrito, por las tendencias moralistas del autor, por la censura (y autocensura) imperante, no pudieran hacerse referencias sexuales explícitas. Por lo tanto, es un recurso muy inteligente emplear la comida para denotar este aspecto. El primer elemento obvio es el nombre de Concha, que comparte con una pieza típica de la panadería popular mexicana.

Así, aunque desde el primer capítulo se insinúa el interés que su compadre José de la Luz tiene por doña Lola, no es sino hasta el capítulo V de la primera parte cuando éste se queda a comer en casa de los Baca, indicando que entabla una relación física con su comadre (39).

Cuando el primer amante de Concha muere en un duelo, llega un general a ocupar su lugar. Concha en un principio no accede a sus peticiones, pero después de una larguísima lucha de voluntades, se 
sobreentiende que ella accede a ser su querida cuando se sienta a la mesa con él (162-66).

Por fin, cuando el coronel Jacobo Baca se ha llevado a su hijo varón, y su hija Concha queda desamparada para siempre, Pío Blanco:

Tan luego como tuvo conocimiento de la vacante, se dirigió a la vinatería de Huergo y se proveyó de ostiones y otras conservas alimenticias, compró Chartreaux verde, licor de los Benedictinos, Aya Pana, Vermouth de Torino, agregó un jamón de Westfalia y un gran trozo de queso fermentado de Gruyére. (223-24)

En los tres casos se manifiesta cómo al convertirse en proveedor, el hombre adquiere derechos sobre la mujer.

\section{6) La comida y la bebida como recurso persuasivo}

Este apartado está estrechamente ligado con el anterior. Ambas formas se emplean de manera constante en el texto. Por ejemplo, cuando Arturo decide comunicarle a Pedrito que su hermana vive con él, pide consejo a Pío Prieto, quien sugiere "entrompetarlo" (100).

Los pollos llegaron a Palacio en coche. Pío Prieto fue a sacar a Pedrito, y los tres se dirigieron en seguida al Tívoli del Eliseo. Era hora de almorzar.

Cuando los pollos hubieron engullido trufas y ostiones, y ya les reventaba el buche a tanta vianda y libación, creyó Arturo llegado el momento de aclarar su situación con Pedrito, y exclamó de repente:

-Somos cuñados. (101)

La feliz escena concluye con los tres amigos brindando con champaña en vasos de un litro. 
Después, cuando Pío Blanco se propone conquistar a Concha, empieza con un alcatraz de dulces:

-...cataplum, me lancé al palco y saludé, provisto de un alcatraz de dulces; lo ofrezco, ella lo acepta, los convido a cenar, bebemos mucha champaña, y después de algunos ponches calientitos... La cosa es hecha. Ya en el champaña, un piececito de la niña me pertenecía; porque han de estar ustedes, que yo acostumbro empezar los telégrafos con los pies: es mi táctica. (129)

\section{7) Otras funciones de la bebida}

Independientemente de la comida, la bebida cumple en el texto con varias funciones específicas. Por ejemplo, medicinal: cuando don Jacobo Baca y los revolucionarios toman los caballos de los habitantes de un poblado y éstos quedan desconsolados, uno de ellos: "Estaba apesadumbrado; luego debía beber pulque" (75). "Tenía tanta fe Marcelino en que el pulque es bueno para las pesadumbres, que le daba pulque a su amigo con la tierna solicitud con que se le da una tisana a un enfermo grave" (idem). Festiva: cuando el compadre José de la Luz le lleva serenata a doña Lola: "A las 'mañanitas' musicales hubo que agregar la indispensable ceremonia de hacer la mañana, y circuló el 'catalán' con beneplácito, especialmente de los músicos" (38). De evasión: la vez cuando Pepe, un amigo de Pío Prieto, fue sorprendido con una flor cortada del jardín público y fue sancionado por su falta, "Pío Prieto y Pepe se dirigieron acto continuo a la pastelería de Plaisant a tomar un ajenjo, licor muy a propósito para aturdirse después de las pasadas emociones" (175).

Por último, cuando Concha va camino de la deshonra absoluta (es decir, camino de Ixtacalco), "comprendió la torva sugestión de las viñas y bebió coñac, con esa tendencia suicida del que pretende huir de sí mismo. De manera que al llegar a Ixtacalco, Concha había encontrado un antídoto contra su vergüenza" (215). 
Así es como se presenta a grandes rasgos el peculiar funcionamiento del discurso alimenticio en un texto singular, que refiere a la sociedad de la Ciudad de México en la segunda mitad del siglo diecinueve: completamente polarizada, en un tiempo de transición entre varios levantamientos armados, víctima de una urbanización incipiente y la consecuente pauperización de la población. Las clases sociales en un momento dado se marcan por una simple diferencia: los que tienen algo para comer y los que no lo tienen. En este contexto es comprensible que los alimentos adquieran tal importancia y se conviertan, por ejemplo, en un elemento persuasivo muy poderoso. De ahí que varios aspectos sean descritos y ambientados en función de la comida, a veces por medio de tropos 0 expresiones coloquiales que tienen relación con ella.

Lo que prevalece ante todo es el afán moralizante del texto. Lo curioso es que la instancia narrativa, en sus larguísimas y constantes digresiones ético-filosóficas, no se limita a criticar de manera explícita la lujuria, la pereza, la envidia y la soberbia: la gula ocupa también un lugar preferente.

A pesar del papel preponderante de la comida en Ensalada de pollos, ésta tampoco constituye una experiencia legítimamente disfrutable. Ningún placer físico parece ser válido en tales parámetros.

\section{Bibliografía}

Cordié, C. "Fisiología del gusto, o Meditaciones de gastronomía trascendente, de Anthelme Brillat-Savarin." Eds. G onzález Porto y Bompiani. D iocionario Literario, t. V, Barcelona: Montaner y Simón, 1959.

Castro Leal. "Prólogo." José Tomás de Cuéllar. H istoria de Chucho el N info y L a N oche Buena. Col. Escritores Mexicanos, núm. 45. México: Porrúa, 1975.

. "Prólogo." José Tomás de Cuéllar. E nsalada de pollos y Baile y Cochino. Col. Escritores Mexicanos, núm. 39. México: Porrúa, 1994. 
Curtius, E. R. Literatura europea y E dad M edia latina, t. I. México: Fondo de Cultura Económica, 1975.

De Cuéllar, José Tomás. E nsalada de pollos y Baile y oochino. Col. Escritores Mexicanos, núm. 39. México: Porrúa, 1994.

D iccionario A suri de la L engua E spañola. Bilbao: Asuri, 1988.

Glantz, Margo. "Ensalada, o la contaminación del discurso." En Margo Glantz, coord. D el fistol a la linterna. H omenaje a José Tomás de C uéllar y M anuel Payno en el centenario de su muerte. México: UNAM, 1997.

Grupo M. Retórica general. Barcelona: Paidós, 1984.

Hjelmslev, Louis. Prolegómenos a una teoría del lenguaje. Madrid: G redos, 1984.

Jakobson, Roman. L ingüística y poética. Madrid: Cátedra, 1984.

Le Guern, Michel. L a metáfora y la metonimia. Madrid: Cátedra, 1990. Pérez Martínez, Héctor. "Facundo en su laberinto." Ed. José Luis Martínez. El ensayo mexicano moderno. México: Promexa, 1985. Van Dijk, Teun A. E structuras y funciones del discurso. México: Siglo XXI, 1980. . Tex to y ontex to. Madrid: Cátedra, 1988. 